\title{
Cocaine-Induced Vasculitis
}

\author{
Mark Berman, M.D. ${ }^{1,2}$, Daphna Paran, M.D. ${ }^{1,2}$, and Ori Elkayam, M.D. ${ }^{1,2 *}$ \\ 'Department of Rheumatology, Tel-Aviv Sourasky MedicalCenter, Tel Aviv, Israel; and 'Sackler Faculty \\ of Medicine, Tel Aviv University, Tel Aviv, Israel
}

\begin{abstract}
ABST RACT
The use of cocaine continues to grow world wide. One of the possible side-effects of cocaine is vasculitis. Two distinct vasculitic syndromes have been described due to cocaine. One is cocaine-induced midline destructive lesion, secondary to a direct vasoconstrictor effect of cocaine, inducing ischemic necrosis of the septal cartilage and perforation of the nasal septum, mimicking findings of granulomatosis with polyangiitis in the upper airways. The other is ANCA-associated vasculitis, attributed to the levamisole component that contaminates about $70 \%$ of the cocaine. This type of vasculitis may be myeloperoxidase (MPO) and proteinase $3\left(\mathrm{PR}_{3}\right)$ positive, and its main manifestations are typical cutaneous findings, arthralgia, otolary ngologic involvement, and agranulocytosis. A high degree of suspicion and awareness is neededin order properly to diagnose and treat these patients.
\end{abstract}

KEY WORDS: Cocaine, levamisole, vasculitis

\section{INT RODUCTION}

The use of cocaine continues to grow worldwide, including in Israel, where it is estimated that around $1 \%$ of individuals between $18-40$ years of age have used cocaine at least once in their lifetime. About $70 \%$ of cocaine is contaminated with levamisole. Two distinct vasculitic syndromes due to cocaine use have been described. The first is cocaine-induced midline destructive lesion (CIMDL), with ischemic necrosis of the septal cartilage and perforation of the nasal septum, mimicking granulomatosis with poly angiitis in the upper airways. The second is antineutrophil cytoplasmic antibody (ANCA)-associated vasculitis attributed to the levamisole component, myeloperoxidase (MPO) and proteinase $3\left(\mathrm{PR}_{3}\right)$

Abbreviations: ANCA, a nti-neutrophil cy toplasm ic a ntibody; CIMDL, cocaine-induced midline destructive lesion; GPA, gr anul om atosis with poly angiitis; HNE, human neutrophil elastase; MPO, myeloperoxidase; PR3, proteinase 3 .

Cit ation: Berman M, Paran D, Elkayam O. Cocaine-Induced Vasculitis. Rambam Ma im onides Med J 2016;7 (4):eoo36. doi:10.5041/RMMJ.10263 Review

Copy right: (C) 2016 Berman et al. This is an open-access article. All its content, exceptw here otherwise noted, is distributed under the terms of the Creative Com mons Attribution License (http://creativecom mons.org/licenses/by/3.0), wh ich permits unrestricted $\mathrm{u}$ se, distribution, and reproduction in any m edium, provided the original work is properly cited.

Conflict of interest: No pot ential conflict of in terest relevant to this article was reported.

* Tow hom correspondence sh ould be a ddressed. E-mail: or ibe14@ netvision.net.il 
positive, whose main manifestations are typical cutaneous findings, arthralgias, otolary ngologic involvement, and agranulocytosis.

Cocaine use and its related complications are well-known public health issues. Cocaine is commonly snorted, inhaled, or injected into the veins. It is estimated that about $1.5 \%$ of the USA population uses cocaine regularly. Israel is not infrequently listed in connection with cocaine in the World Drug Report for 2013, issued by the United Nations Office on Drugs and Crime, which discusses trends in the world. ${ }^{1}$ It is difficult to find up-to-date figureson the scope of cocaine trafficking at the local level in Israel. However, the latest survey (from 2009) by Israel's Anti-Drug Authority on cocainenoteda clear trend: cocaine use had doubled by 2009 compared with 2005 , and close to $1 \%$ of all Israelis aged $18-40$ years indicated that they had used cocaine.

The toxic effects of cocaine include possibly irreversible structural changes of the brain, heart, lung, and other organs, such as the liver and kidney. ${ }^{2} \mathrm{~A}$ 2009 USA national survey found that $70 \%$ of cocaine is contaminated by levamisole. 3,4 Levamisole, a medication used to treat parasitic worm infection, is added to cocaine because it potentiates its stimulant effects by inhibiting both monoamine oxidase and catechol-O-methyltransferase activity, thereby prolonging the action of catecholamines in theneuronal sy napse and increasing the reuptake inhibition. In addition, levamisole reacts like cocaine in the "bleach test," a quick, widely utilized street test for cocaine purity. Therefore, it adds weight to illicit cocaine without reducing the native drug's apparent purity, as occurs with other bulking agents such as sugar or lidocaine. 4

Originally marketed as an anti-helminthic agent, levamisole was also found to have major immunomodulatory properties, and it was therefore used to treat colon cancer, rheumatoid arthritis, and pediatric nephrotic syndrome. Reports of neutropenia led to its withdrawal from the USA market in 1999, although it is still used as a deworming agent in veterinary medicine, and it is still marketed as an anti-helminthic and immunomodulatory agent in some countries.

Importantly, some of the toxic effects of cocaine are attributable to levamisole. There is growing recognition oflevamisole-induced agranulocytosis, vasculitis, midline destructive lesions, and other complications in cocaine users. One of the less known effects of cocaine use is its ability to induce several types of vasculitis, especially those that mimic ANCA-associated vasculitis. Two ty pes of cocaineinduced syndromes have been described over the past two decades: one is directly related to the local effects of snorting cocaine that may lead to midline destructivelesions and therefore mimics vasculitis lesions found in granulomatosis with poly angiitis (GPA), and the other is attributed to levamisole and behav es like drug-induced ANCA-associated vasculitis.

\section{COCAINE-INDUCED MIDLINE DEST RUCT IVE LESIONS}

Nasal insufflation of cocaine may cause lesions in the mucosa. Progressive damage of the mucosa and perichondrium associated with chronic cocaine use leads to ischemic necrosis of the septal cartilageand perforation of the nasal septum. The mucosal damage induced by cocaine is multifactorial, with the vasoconstrictive effect of the drug thought to be the most important factor. 5 $^{-7}$ However, the irritant effect of the adulterants of the drug, the traumatic effect on the mucosa caused by cocaine crystals insufflated at high v elocity, and the recurrent nasal infections all seem to contribute to chronic tissue destruction. ${ }^{6,8}$ Cocaine-induced lesions occasionally cause extensive destruction of the osteocartilaginous structures of the nose, sinuses, and palate thatmimics the clinical picture of other diseases associated with necrotizing midfacial lesions.7 Progressive nasal obstruction, epistaxis with crusting, and ulceration of the nasal mucosa with or without septal perforation are also characteristic manifestations of nasal involvement by GPA. The differentiation between CIMDLs and limited GPA may be difficult, particularly if the patients do not mention their substance abuse.

Anti-neutrophil cytoplasmic antibodies directed against PR3 or MPO are sensitive and specific markers for the idiopathic small-vessel vasculitides, including GPA. The presence of a positive ANCA test result with either of those two markers points to the differential diagnosis of GPA. However, positive ANCA test results were found in an unex pectedly large proportion of cocaine-abusing patients with CIMDL whose lesions were clinically indistinguishable from GPA limited to the upper respiratory tract in several cases. 9 Trimarchi et al. 7 compared the clinical, serologic, radiographic, and histopathologic features of 18 consecutive patients who presented with CIMDL with those of 21 patients withGPA with nasal involvement who were being evaluatedduring 
the same time period. Routine ANCA tests were positive in 13 of the 18 CIMDL patients compared with 19 of 21 GPA patients. Clinical and radiographic evaluations revealed that destruction of facial midline structures was significantly more severe in CIMDL than in GPA. Although biopsies with nonspecific changes were more frequent in CIMDL, and leukocytoclastic vasculitis and fibrinoid necrosis were more frequent in GPA, both were reported in the two pathologies and therefore did not contribute to the diagnosis of individual patients. In contrast to GPA, there was no other organ involvement and no significant laboratory abnormalities indicating systemic inflammation in CIMDL. Detailed analy sis of the ANCAs found in the CIMDL and GPA patients showed that none of the eight perinuclear ANCAsin CIMDL patients reacted with MPO, while four reacted with $\mathrm{PR}_{3}$, three with human neutrophil elastase (HNE), and two had double positivity to $\mathrm{PR}_{3}$ and HNE. All of the five cytoplasmatic ANCAs reacted with $\mathrm{PR}_{3}$, and two of them also reacted with HNE. In contrast, 18 of the 19 ANCA-positive GPA patients displayed concurrent $\mathrm{p}$-/MPO-ANCA or c/PR3-ANCA reactivity.

It is known that $\mathrm{HNE}$ and $\mathrm{PR}_{3}$ belong to the same family of serine proteases. Wiesner et al. ${ }^{10}$ reported an unexpectedly high frequency (84\%) of HNE ANCAs in patients presenting with CIMDL. In contrast, no HNE ANCAs were detected in their patients with GPA or microscopic polyangiitis, and HNE ANCAs were detected only rarely in patients with other autoimmune diseases or vasculitis. Many of the sera obtained from patients with CIMDL also reacted with PR3. Consequently, those authors concluded that HNE ANCAs occurring in patients with midline destructivelesions may discriminate between CIMDL and GPA.7,10

\section{LEVAMISOLE-INDUCEDVASCULITIS}

As noted before, approximately $70 \%$ of cocaine in the USA is contaminated with levamisole. A growing number of reports describing levamisole-induced vasculitis have appeared during the last 20 years. The first report was published as a case series in 1999. ${ }^{11}$ Five children who were treated with levamisole for nephrotic syndrome for an average of 24 months developed purpuric and erythematous macules, rapidly enlarging necrotic areas, purpuric papules/ plaques, and hemorrhagic bullae.Skin involvement of the external ears was present in all patients. Subsequent case studies with a similar profile of skin findings confirmed this association. The lesions usually were resolved by 2-3 weeks after drug discontinuation.

The first report of vasculitis induced by lev amisole-contaminated cocaine was published in 2010 , and the condition was characterized by typical cutaneous findings, agranulocytosis/neutropenia, and a positive ANCA. ${ }^{12}$ Several similar case reports later appeared in the literature.

McGrath et al. ${ }^{13}$ described ANCA-positivity associated with levamisole-contaminated cocaine. In their study, 327 new ANCA-positive patients during 2009-2010 were identified and reviewed. Active cocaine use was identified in 30 cases. The medical records of 18 active cocaine users were available for review: 16 had skin manifestations consisting of necrotic lesions $(n=3)$, purpura $(n=6)$, digital abscesses $(n=1)$, ecchymotic bullous skin lesions $(n=1)$, and purpuric lesions over earlobes $(n=5)$ as described in classic levamisole-induced vasculitis. Arthralgias were reported in $83 \%$, which generally involved the large joints. A total of $72 \%$ of patients reported at least one constitutional symptom such as fever, night sweats, weight loss, malaise, or myalgia. Otolaryngologic involvement was present in $44 \%$ of cases, most commonly sinusitis and recurrent rhinorrhea. Twenty-eight percent of patients had leucopenia at presentation; four patients had an absolute neutrophil countbelow 100, and one had profound leucopenia requiring granulocy te macro phage colonystimulating factor. Abnormalurinalysis was present in eight patients at diagnosis, and two of them developed severe acute renal failure. One patient underwent kidney biopsy revealing pauci-immune focal necrotizing and crescentic glomerulonephritis. Pulmonary hemorrhage, not requiring intubation, was reported in three patients; none of them had impairment of renal function. Overall, there was no definitive evidence of pulmonary-renal syndrome in this cohort. ${ }^{13}$

On biopsy, skin lesions may show thrombotic vasculopathy, vasculitis, or a combination of the two. The vasculitis is believed to be immunemediated based on the presence IgM, IgG, IgA, and $\mathrm{C}_{3}$ complexes. There are very few reports of biopsies of internal organs: one renal biopsy in a patientwith acute kidney injury revealed pauci-immune focal necrotizing and crescentic glomerulonephritis. ${ }^{14-16}$

Levamisole-induced vasculitis has unusual autoantibody findings. High-titer perinuclear ANCAs are almost always present (86\%-100\%), and about 50\% of the cases also hav e cytoplasmic ANCA s. ${ }^{13}$ How- 
ever, the specific antigens responsible forgenerating these positive ANCA fluorescent patterns arenotyet clearly defined. Antibodies against myeloperoxidase (anti-MPO), the antibody most often responsible for a perinuclear ANCA pattern, are found in almost every case. Importantly, anti-MPOtiters in cocaineassociated ANCAs may be very high, up to 15 -fold higher than in patients with idiopathic ANCAassociated vasculitis. ${ }^{13}$ Antibodies against $\mathrm{PR}_{3}$, the autoantibody most commonly associated with a cytoplasmic ANCA pattern, are present in about $50 \%$ of these patients, but they may be directed against HNE because of cross-reactivity, as noted earlier in connection with CIMDL.

Levamisole-induced vasculitis remains a challenging diagnosis. It may not be initially suspectedif patients are not queried about illicit drug use or if they deny drug use when questioned. It is possible to perform a urine drug toxicology screen because cocaine remains in the urine for 48 to 72 hours following use. A definitive connection to levamisole may, however, be difficult to establish even with a positive cocaine screen because levamisoleis rapidly absorbed and has a short half-life (5.5-6 hours). A recent study demonstrated that over two-thirds of urine samples positive for cocaine had detectable levels oflevamisole on gas chromatography / mass spectroscopy. ${ }^{17}$ That study was carried out in an inner-city emergency department, and it emphasized the need for a very high degree of clinical suspicion early in disease presentationin order definitively to confirm exposure.

Management of levamisole-induced vasculitis is supportive. The cornerstone of treatment is halting further exposure to cocaine. Medicaltreatmentmay include wound dressing and antibiotics in superimposed infections. Some untreated cutaneous lesions may regress in a few weeks after stopping cocaine use. ${ }^{18}$ There is currently no evidence that systemic corticosteroids modify the clinical course, but they may be reserved for cases that are unresponsive to supportive therapy alone, e.g. debilitating arthropathy, strikingly elevated C-reactive protein levels, or biopsy-proven vasculitis. ${ }^{19}$ Noncompliance with therapy and ongoing cocaine use make this a challenging patient group to manage.

\section{CONCLUSIONS}

Cocaine abuse is an expanding public health concern. Cocaine-inducedvasculitis may present in different forms. Snorting cocaine may induce mid- line destructive lesions which are often ANCApositive and which may be indistinguishable from otolaryngologic lesions of GPA. Aggressive local midline destruction, lack of systemic symptoms, and HNE ANCA-associated antibodies may point toward a cocaine-induced lesion. The other cocaine-induced vasculitis phenotype, systemic ANCA-associated vasculitis, is due to the levamisole componentof the drug. It is characterized by typical hemorrhagic skin lesions, leucopenia, rare renal involvement, andvery high titers of perinuclear and cytoplasmic ANCAassociated autoantibodies. Cessation of cocaine use is essential and may be the only step required to resolve this clinical condition. In view of the increasing use of cocaine, a high degree of suspicion and awareness is needed in order properly to diagnose and treat patients with cocaine-induced vasculitis.

\section{REFERENCES}

1. UNODC. World Drug Report 2013 (United Nations publication, Sales No. E.13.XI.6).

2. Riezzo I, Fiore C, De Carlo D, et al. Side effects of cocaine abuse: multiorgan toxicity and pathological consequences. Curr Med Chem 2012;19:5624-46. Full Text

3. Gross RL, Bru cker J, Bahce-Altuntas A, et al. Anovel cutaneous vasculitis syndrome induced by lev amisole-contaminated cocaine. Clin Rheu matol 2011;30:1385-92. Full Text

4. Chang A, Osterloh J, Thomas J. Levamisole: a dangerou s new cocaine adulterant. Clin Pharmacol Ther 2010;88:408-11. Full Text

5. Daggett RB, Haghighi P, Terkeltaub RA. Nasal cocaine abuse causing an aggressive midline intranasal and pharyngeal destructive process mimicking midline reticulosis and limited Wegener's granulomatosis. J Rheumatol 1990;1 7:838-40.

6. Deutsch HL, Millard DR. A new cocaine abuse com plex. Involvement of nose, septum, palate, and pharynx. Arch Otolaryngol Head Neck Surg 1989;115:235-7. Full Text

7. Trimarchi M, Gregorini G, Facchetti F, et al. Cocaineinduced midline destructive lesions: clinical, radiographic, histopathologic, and serologic features and their differentiation from Wegener granulomatosis. Medicine (Baltimore) 2001;80:391-404. Full Text

8. Kuriloff DB, Kimmelman CP. Osteocartilaginous necrosis of the sinonasal tract following cocaine abuse. Laryngoscope 1989;99:918-24. Full Text

9. Gregorini G, Facchetti F, Morassi L, et al. Positive ANCA tests in patients with cocaine induced midline 
destructive lesions (CIMDL). Clin Exp Immu nol 2000;1 $20($ Suppl 1):59.

10. Wiesner O, Russell KA, Lee AS, et al. Antineutrophil cy toplasmic antibodies reacting with human n eutrophil elastase as a diagnostic marker for cocaineinduced midline destructive lesions but not a utoimmunevasculitis. Arthritis Rheum 2004;50:2954-65. Full Text

11. RongiolettiF, Ghio L, Ginevri F, et al. Purpura of the ears: a distinctivevasculopathy with circulating autoantibodies com plicating long-term treatm ent with lev amisole in children. Br J Dermatol 1999;140:94851. Full Text

12. Bradford M, Rosenberg B, Moreno J, Dumy ati G. Bilateral necrosis of earlobes and cheeks: another complication of cocaine contaminated with levamisole. Ann Intern Med 2010;152:758-9. Full Text

13. McGrath MM, Isakova T, Rennke HG, Mottola AM, Laliberte KA, Niles JL. Contaminated cocaine and antineutrophil cy toplasmic antibody -a ssociated disease. Clin J Am Soc Nephrol 2011;6:2799-805. Full $\underline{\text { Text }}$

14. Culpepper K, Kessler M. Levamisole-induced thrombosis: liter ature review and pertinent laboratory findings. J Am Acad Dermatol 2011;65:e128-9. Full Text
15. Chung C, Tumeh PC, Birnbaum R, et al. Characteristic purpura of the ears, vasculitis, and neutropenia - a potential public health epidemic associated with levamisole-adulterated cocaine. J Am Acad Dermatol 2011;65:722-5. Full Text

16. Jacob RS, Silva CY, Powers JG, et al. Lev amisoleinducedvasculopathy: a report of 2 cases and anovel histopathologic finding. Am J Dermatopathol 2012; 34:208-13. Full Text

17. Buchanan JA, Heard K, Burbach C, Wilson ML, Dart R. Prevalence of levamisole in urine toxicology screen s positive for cocaine in an inner-city hospital. JAMA 2011;305:1657-8. Full Text

18. Patnaik S, Balderia P, Vanchhawng L, Markazi P, Wy kretowicz J, Perloff S. Is levamisole-induced vasculitis a relegated diagnostic possibility? A case report and review of literature. Am J Case Reports 2015;16:658-62. Full Text

19. Pear son T, Bremmer M, Cohen J, Driscoll M. Vasculopathy related to cocaine adulterated with levamisole: a review of the literature. Dermatol Online J $2012 ; 18: 7$. 